MATEC Web of Conferences 52, 02004 (2016)

DOI: $10.1051 /$ matecconf/20165202004

(C) Owned by the authors, published by EDP Sciences, 2016

\title{
Product System Design - to Household Massage Design as An Example
}

\author{
Wang Huabin ${ }^{1}$, Lin Qichao ${ }^{2, a}$ \\ ${ }^{1}$ Industrial Design, South China University of Technology School of Design, University town, Panyu district, \\ Guangzhou ,Guangdong Province, China \\ ${ }^{2}$ Industrial Design, South China University of Technology School of Design, University town, Panyu district, \\ Guangzhou ,Guangdong Province, China
}

\begin{abstract}
Explain what is the system design and the applications of System design in the product design process. Using The whole idea and systems design methods to analyze the design of household hand massage, Use a chart image to explain that Household hand massage products in the influence of user and the environment, the influence of large system environment for the product. The use of components of the system to anatomy product design . Each system components has a link between and mutual correlation.
\end{abstract}

\section{System Design and the Basic Framework of Product System Design}

Product system design has two meanings, One is the design object is no longer isolated, but put it in the relevant system in consideration; Secondly, a single product also be regarded as a system made up by more than one unit, and in order to realize the product in the use of functional interchange ability, flexibility and infinite complementary.[1]

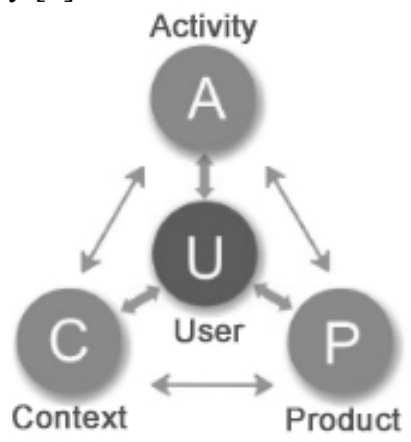

Figure 1-1. the basic framework of UACP product system design.

"Interaction design", points out that in the field of Product design related to industrial design, can use the User, Activity, Context and Product four elements to constitute the basic framework of UACP Product system design.[2] The product is designed by the Interactive system environment of PACT

${ }^{\text {a }}$ Corresponding author : littlepig199112@hotmail.com 
posed organic, PACT is short for interactive system elements, People (People), behaviour (Activity), the product when using the scene (Context) and the integration of Technology in products (Technology).[3] The analysis of the nature of the product and function through elements of the system, emphasizes the system constitute harmony of elements, Emphasize the interactive function of product in the use of the environment, focus on the user and the product system experience in the process of information exchange. Products can be derived from two kinds of design patterns, "peoplethings" system," people-things - environment" system.

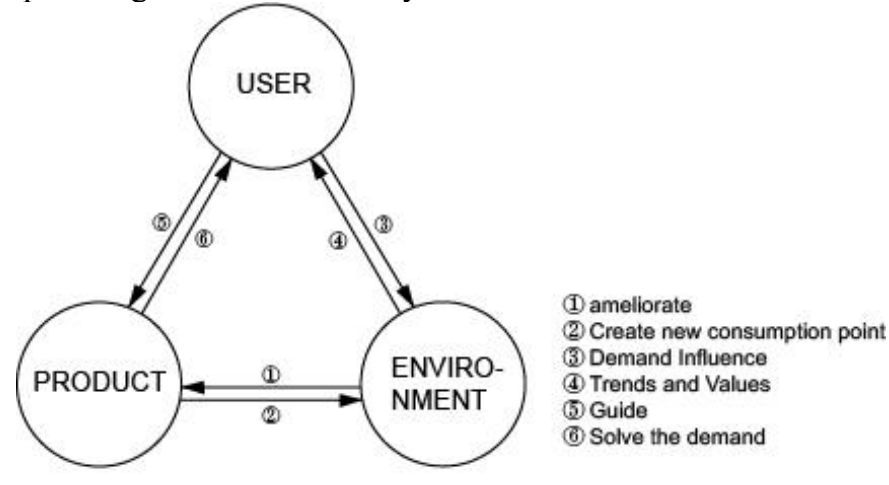

Figure 1-2. " people - things - environment " system model

\section{The household hand massage products system}

Household hand massage product is implicated in multiple systems analysis and design. Designers should think deeply products from the perspective of system design, design and develop Systematic solution with products as the core.

\subsection{User}

Use of the method of qualitative characters from the user research to determine the target user. Based on qualitative research, interviews, field observation and usability testing, creating characters, according to the user's goals, find some views and behavior model, subdivide each group to create a character. Unified the target group is the concept of fuzzy, tend to sit for a long time, believe and understand massage physical function, often feel body muscle tension and mental pressure of the crowd. Designing products by the characteristics of the user. products, behavior and situations can affect ideas and new knowledge of users.[4]

\subsection{Behavior}

User research methods observed user behavior, this type of users who sit for a long time don't like the use of complex means and methods, so the key to attract the users of this type are how to relieve pressure and muscle tension by massage and human-computer interaction.

\subsection{Situation}

After determine the target user groups, with the overall system design method to consider the use of the user. Products are communication between people and things in a situation and moment, for realizing people's needs, Products are to rely on the scene. 


\subsection{Product}

The product is the core of the system components, including tangible products and intangible product (service). For the product of relieve stress, and sometimes the user need may not be the product itself, but the back of a product service. Product form of entity is broken, makes the product is not only physical properties can also as a bridge connecting people to achieve real communication.

In the application of home massage products in two kinds of system model

"people-things" system: household massage product properties by material function to the user, to meet their material needs.

" People - things - environment " system: People in contact with the product that have an effect on society and the surrounding environment, at the same time, people affected products, the environment also affect a person, actually is a cyclic process. Products in addition to meet the user's physiological needs need to meet the needs of psychology, psychological demand is closely linked with people in the environment. " people - things - environment " is a large system. The mutual influence between them. (as shown in figure 2-1)

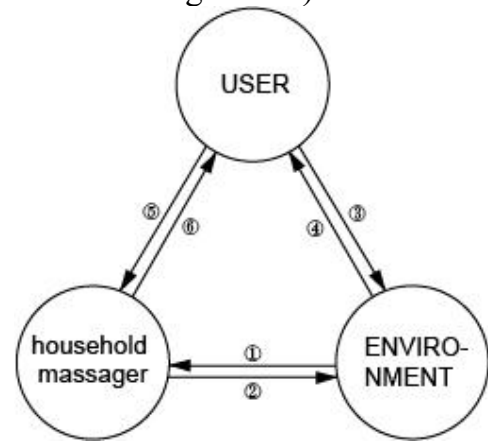

(1) A new technology to improve the massage way

Trend leading new materials and new pattern

(2) Create new consumption point

(3) Demand impact of the new products come out

(4) Effect of massage habits, ways and new ideas

(5) Behavior guide the operating instructions of the product

better improve massage the perfection of the function of the product layer

(6) Massage to relieve stress and muscle tension

Figure 2-1. "household massage - User - the external environment " system model. The relationship between the system and influence each other

"Household massage - User - the external environment " system model.System link belong to each other between the universality of specificity, in view of the system with different products is the practical.

The entire product internal system and external system linked to each other, the relationship between the internal system is the product of the whole system, there are four basic elements. External system is the external environment, which include the existing technical environment, use of environment and economic environment, etc. Between them is through the whole system connect with each other, influence each other (as shown in figure 2-2)[5]

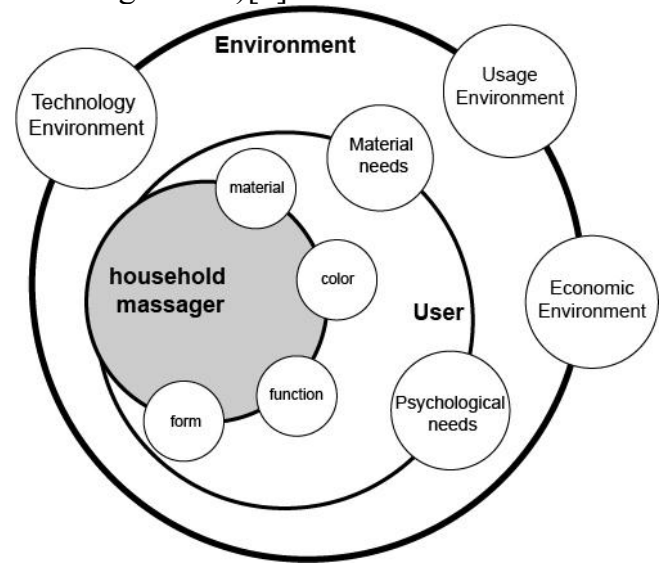

Figure 2-2. the relationship between the internal system and external system 


\section{Household Massage Products System Components, And Feedback In Research}

Household system elements are: material elements, color elements, function, shape, etc. The early stage of the analysis of product by using the principle of the system design, research of the product elements and sums up their advantages is to master the whole industry situation and understand the design direction has important guiding role.[6]

Materials can be found through the actual investigation form elements, color elements, function, shape elements influence each other, interaction are shown in table 3-1

Table 3-1. household massage products system elements of network survey table

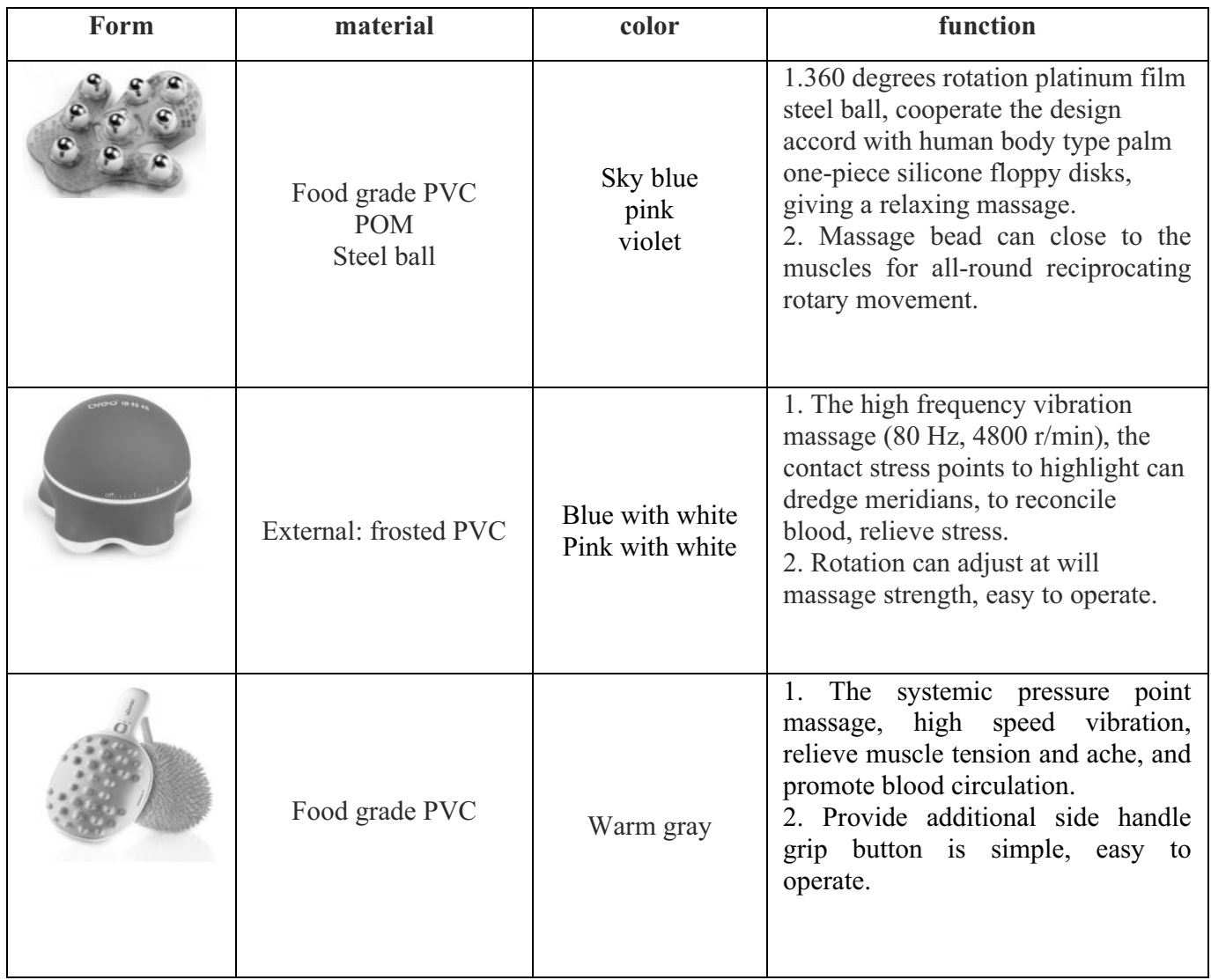

Material elements: as the product is rich, material limits for the product are gradually being broken. Now home massage products material is also in the implementation of new reform, mixing of different material, the use of different materials, the combination of soft and hard materials to the user the use effect of different, the use of the user behavior is more smooth and perfect.

Color: Color is an important language and elements in the product design. After a lot of experts and scholars of research confirms that color can affect the person's psychology. the color of household hand massage should be required to calm the user's psychological pressure, and also has the very good affinity.

Functional elements: function is the primary elements of products. "Not completely without any function of the object in the world, since its objective existence is inevitably has its reason to exist", the stand or fall of the function of a product design is often the most direct performance, meet the demand of the user functions in terms of product availability and ease of use is one of the main evaluation criteria. Household hand massage should be based on function of massage, different 
massage way also concerns of the functional factors, at the same time satisfy the basic function according to the previous research, to access to the user's access to survey method, seek the function of the user's real needs, such as heating, mobile massage and so on.

Form elements: form is the most direct the actual image of a product to users, is one of the most powerful factor to improve product added value. Household hand massage morphology according to the function to decide, according to the user's psychological needs. Previous research in the form of different products can realize different function, produce the advantages and disadvantages of product evaluation, can very good lead the implementation of the new, improved product form.[7]

\section{Summary}

Product design is to have the idea of the overall consideration of each system, each element in the system and the relationship between each system. The whole is greater than the part, the overall could not be isolated and focus on a part of the system .we should integrally look at a part need to meet the consumer demand of whole product design. Product system, the user's system, external environment system sometimes appears to be no relationship between them, actually have a deep affinity.

\section{References}

1. Jiang Wen. System design---A Way for Combining the Function of Products. Chinese Journal of Engineering Design. 28( 2001)

2. Zhou Fei. Deng Rong. Li Shiguo. Research on Fuzzy on the Product Interaction Design PACKAGING ENGINEERING 34 39-40（2013）

3. David Benyon,. Phil Turner. Susan Turner. Designing Interactive Systems. Pearson Education Limited. 65-72 (2005)

4. Don Norman. Emotional Design .Basic Books (2005)

5. Rao Heng. Research On System-product Design Of Tea set Based On The SpD Theory [D].Guangdong University of Technology. 34-37 (2012)

6. Cai Ke. The Element Analysis of Product System Design [D]. Wuhan University of Technology $10-18(2008)$

7. Rao Heng. Research On System-product Design Of Tea set Based On The SpD Theory [D].Guangdong University of Technology. 34-37 (2012) 